\title{
Nickel-Catalyzed Ipso-Borylation of Silyloxyarenes via C-O Bond Activation
}

\author{
Wesley L. Pein, Eric M Wiensch, and John Montgomery* \\ Department of Chemistry, University of Michigan, 930 N. University Ave., Ann Arbor, MI, 48109-1055, USA.
}

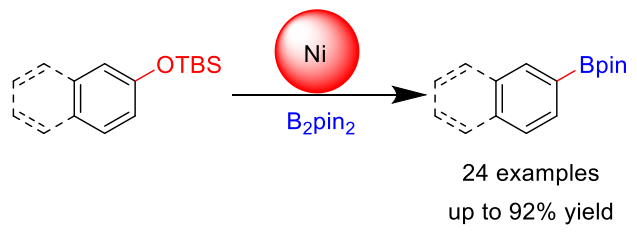

ABSTRACT: A mild method to convert silyloxyarenes to pinacol boronic esters using nickel catalysis is described. In contrast to other borylation protocols of relatively inert $\mathrm{C}-\mathrm{O}$ bonds, the method is competent in activating the carbon-oxygen bond of silyloxyarenes in isolated aromatic systems lacking a directing group. The catalytic functionalization of benzyl silyl ethers was also achieved under these conditions. Orthogonal reactivity of silyloxyarenes vs other electrophiles was demonstrated in the case of several cross-coupling reactions wherein the unaffected silyloxarene could be functionalized subsequently.

In recent years, employing earth-abundant base-metals including nickel for catalysis has been of great interest due to their ability to provide a more sustainable and affordable option while offering unique reactivity compared with precious metal alternatives. ${ }^{1}$ In pursuit of this goal, much has been learned regarding the special properties of nickel that differentiate it from its congener palladium, such as nickel's unique propensity to activate low-reactivity $\mathrm{C}-\mathrm{O}$ bonds. ${ }^{2}$ Developing cross-coupling reactions that employ $\mathrm{C}-\mathrm{O}$ electrophiles is desirable due to the abundance and diversity of phenol derivatives that are commercially available and present in natural products. Furthermore, the reactivity of the $\mathrm{C}-\mathrm{O}$ bond can be modulated greatly depending on the protecting group being employed (Scheme 1).

Taken together, aryl halides and phenol derivatives provide a wide range of reactivity and stability, which presents opportunities for orthogonal reactivity among different substrate classes utilized in cross couplings. ${ }^{3}$ This enables functionally dense aryl scaffolds possessing differentiated electrophilic sites to be engaged in sequential couplings via judicious selection of catalyst type. Whereas a diverse range of effective cross-coupling methods have been developed utilizing aryl halides, triflates, and pivalates, methods employing low-reactivity aryl $\mathrm{C}-\mathrm{O}$ electrophiles such as simple ethers often require either harsh, organometallic nucleophilic coupling partners such as Grignard reagents, highly activated naphthol-derived electrophiles, and/or direct groups that promote reactivity. To bridge this gap, we decided to utilize silyloxyarenes as coupling partners. Although silyloxyarenes have most commonly seen usage in reactions with activated nucleophilic coupling partners, ${ }^{4}$ recent reports from our lab show that electron-rich nickel $N$-heterocyclic carbene (Ni-NHC) catalyst systems facilitate the reduction, silylation, and amination of silyloxyarenes in a manner that is inclusive of isolated aromatic systems without the need for orthodirecting groups. ${ }^{5,6}$

In this report, we sought to expand this work to include borylation, as aryl boronic acid pinacol esters serve as excellent handles for downstream functionalization ${ }^{7}$ and serve as precursors for medicinally relevant boronic acids ${ }^{8}$ (Scheme 1).

Scheme 1. Couplings of Aryl Ethers.

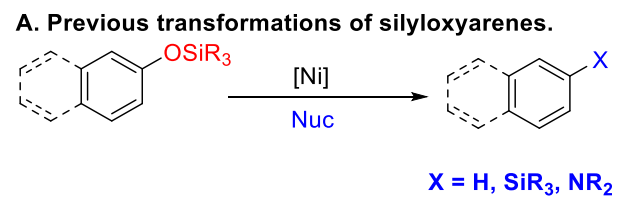

B. Borylation of inert C-O electrophiles.

previous work:

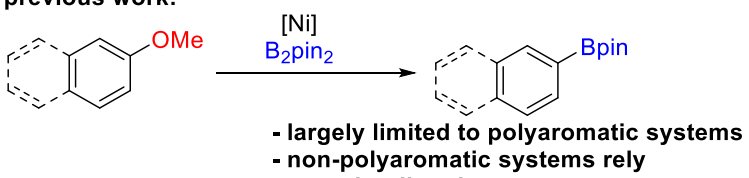

this work: on ortho directing groups

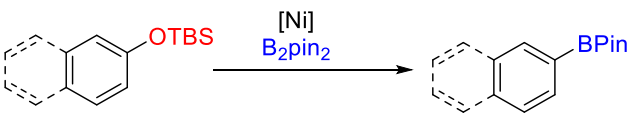

- orthogonal reactivity to other methods - distuinguishes between $\mathrm{C}\left(\mathrm{sp}^{2}\right) \mathrm{O}$ and $\mathrm{C}\left(\mathrm{sp}^{3}\right) \mathrm{O}$ bonds

- extended scope

Traditional synthetic organic methods to access aryl boronic acids involve the treatment of borates with organolithium reagents. ${ }^{9}$ Attractive methods have also been described for the light-mediated and transition metal-catalyzed reactions enabling the borylation of aryl halides and aryl $\mathrm{C}-\mathrm{H}$ bonds. ${ }^{10}$ More recently, $\mathrm{C}-\mathrm{O}$ electrophiles have been utilized as precursors to aryl boronic acids, although these transformations do exhibit limitations. For example, borylations of pseudohalides and pivalates can be sensitive to strong bases like tert-butoxide, and thus rely on weaker Lewis bases to activate the diboron. ${ }^{11,12}$ While less sensitive to base, carbamates still suffer from decreased reactivity regarding isolated aromatic systems as they take $48 \mathrm{~h}$ to afford appreciable yields of desired product. ${ }^{13,14}$ Being the most stable, methyl ethers are tolerant to promotion by alkoxide bases, however, this class of transformations is not 
effective with isolated aromatic systems unless an ortho-directing group is present. ${ }^{15}$

To address the above limitations regarding $\mathrm{C}-\mathrm{O}$ activation methods for cross coupling, silyloxy arenes offer a number of promising attributes. They offer ease of synthesis, stability in an array of multistep reaction sequences, and well-understood reactivity profiles, owing to detailed investigations of silyl ethers as protecting groups. This latter understanding gives rise to predictable strategies to tune their reactivity and stability across a range of reaction conditions, ${ }^{16}$ enabling them to be carried through several synthetic steps, functionalized without additional deprotection and activation steps, and manipulated in late-stage diversification processes. Given the ideal balance between the stability and reactivity of silyloxyarenes in comparison to other inert $\mathrm{C}-\mathrm{O}$ electrophiles, this study sought to enable the inclusion of substrates that go beyond naphthyl systems while using attractive diboron coupling partners.

Optimization efforts utilizing TBS-protected substrate $\mathbf{1}$ were first explored based on our previous studies of silyloxyarene aminations and reductions, wherein electron rich Ni-NHC catalyst systems were shown to be effective in conjunction with $t$-butoxide bases in toluene with $\mathrm{Cu}(\mathrm{OAc})_{2}$ to aid the transmetallation step (Scheme 2). ${ }^{5,6,17}$

Scheme 2. Preliminary Hit.

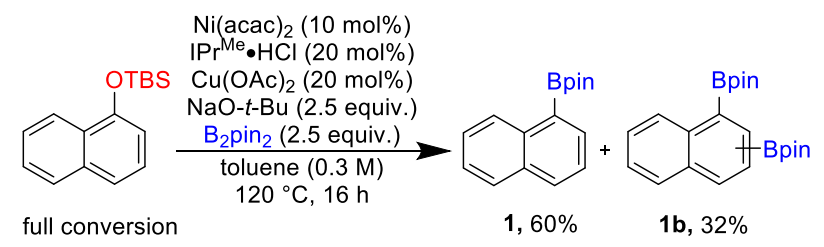

Under these conditions, however, low yields and overborylation of the desired product providing a mixture of regioisomers was observed (1b, Scheme 2) along with borylation of the toluene solvent. ${ }^{18,19}$

Further optimization was conducted with a silylated 3phenylphenol derivative as the model substrate, as we anticipated that optimization around this substrate would address the challenges of $\mathrm{C}-\mathrm{O}$ activations in biphenyls and isolated aromatic systems. To eliminate side product formation resulting from the borylation of solvent, non-arene solvents were investigated, starting with ethereal solvents that matched the boiling point profile for the requisite reaction temperature (Table 1, entries 1-2). The utilization of cyclopentyl methyl ether (CPME) as the solvent greatly enhanced the yield of the desired product and eliminated solvent-derived side products. Furthermore, it was found that in this solvent, $\mathrm{Cu}(\mathrm{OAc})_{2}$ was no longer required to promote the reaction, though it did not hinder yields (Table 1, entry 3 ).

Representative $\mathrm{Ni}(0)$ and $\mathrm{Ni}(\mathrm{II})$ salts were screened, but were found to not be as effective as $\mathrm{Ni}(\mathrm{acac})_{2}$ (Table 1, entries 4-5). Phosphine ligands were ineffective (Table 1, entry 6), and incorporation of methyl groups on the NHC backbone were essential for optimal reactivity as notable yield decreases were observed with IPr $\bullet \mathrm{HCl}$. Although $\mathrm{IPr}^{* \mathrm{OMe}} \cdot \mathrm{HCl}$ had been effective in reductions of silyloxyarenes, it was not effective in borylations. (Table 1, entry 7-8). The choice of counterion of the base was examined, and $\mathrm{LiO}-t$-Bu was optimal as $\mathrm{NaO}-t-\mathrm{Bu}$ delivered product in slightly lower yields. Lastly, equivalents of $\mathrm{B}_{2} \mathrm{pin}_{2}$ were reduced to minimize overborylation, but yields were greatly reduced, while increasing $\mathrm{B}_{2}$ pin $_{2}$ offered a neglible change in yield (Table 1, entries 10-11).

Table 1. Optimization for the Borylation of Silyloxyarenes.

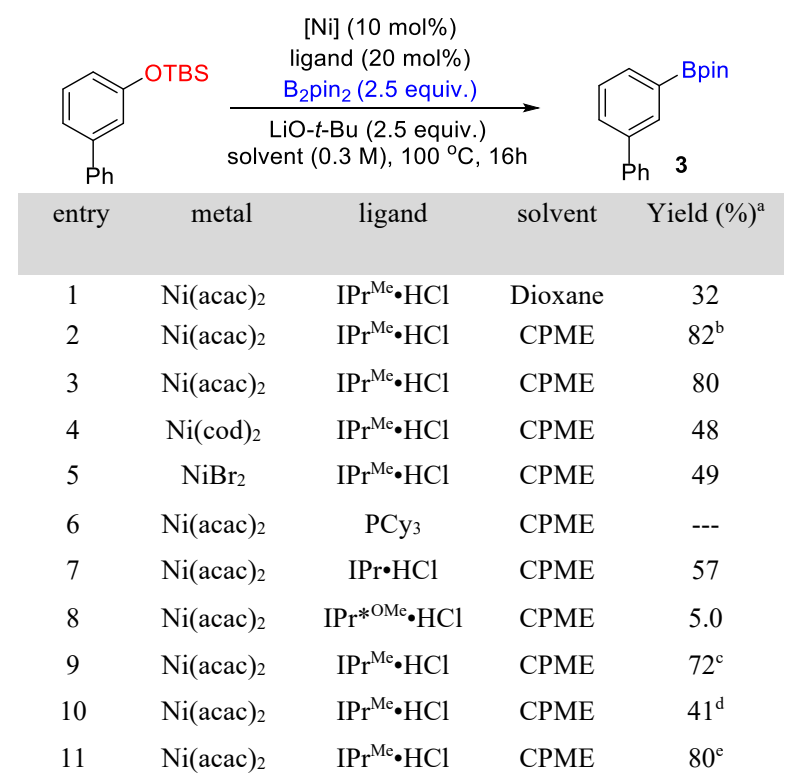

${ }^{a}$ Yields were determined by ${ }^{1} \mathrm{H}$ NMR with $\mathrm{CH}_{2} \mathrm{Br}_{2}$ as internal standard. ${ }^{\mathrm{b}} \mathrm{Cu}(\mathrm{OAc})_{2}(20 \mathrm{~mol} \%)$ was added. ${ }^{\mathrm{NaO}}-\mathrm{t}-\mathrm{Bu}$ used instead of $\mathrm{LiO}-t$-Bu. ${ }^{\mathrm{d}} \mathrm{B}_{2}$ pin 2 (2.0 equiv.), LiO-t-Bu (2.0 equiv.). ${ }^{\mathrm{B}} \mathrm{B}_{2} \mathrm{pin}_{2}$ (3.0 equiv.), LiO- $t$-Bu (3.0 equiv.).

With optimized conditions in hand, the scope of the ipsoborylation of silyloxyarenes was explored (Scheme 3). The reaction conditions were quite broad, providing good to excellent yields for a variety of silyloxyarenes without deviating from the standard conditions, and in no case was the Suzuki byproduct derived from further reaction of the aryl BPin, observed. For naphthyl and biphenyl systems, full conversion was generally observed, wherein the remaining mass balance could be attributed to over-borylated of the desired product, resulting in a mixture of regioisomers. Unfortunately, optimization efforts did not improve conversion of starting material to desired product; however, it is worth noting that borylation can be achieved at both the 1 and 2 position of the naphthyl unit in the cases of compounds 1 and $\mathbf{2}$ (Scheme 3). A more favorable product distribution was observed with the less activated biphenyl (compound 3, Scheme 3) systems, although reduced yields due to over-borylation were still observed to some extent. A biphenyl system possessing substitution at the 4 position proved to be less susceptible to this issue, providing excellent yield of the desired product, likely due to the substrate inhibiting overborylation due to its increased steric profile (compound 4, Scheme 3).

Notably, the reaction converted isolated aromatic systems in excellent yields, and in these cases, the remainder of the mass balance was typically starting material and small quantities proto-deborylation product (compounds 5 and 6, Scheme 3). The reaction proved to be tolerant of sterics both at the ortho position and at other sites around the ring even in isolated aromatics (compounds 7-8, 11, Scheme 3). Tolerance to sterics was improved when biphenyl scaffolds were subjected to reaction conditions (compounds 9 and 10, Scheme 3). Electron-donating substrates were examined, demonstrating that oxygen and 
nitrogen groups could be incorporated (compounds 13, 15, Scheme 3); however, when the electron-donating group was at the para position, decreases in yield were observed (compounds 12, 14, Scheme 3).

Scheme 3. Scope for Borylation of Silyloxyarenes.
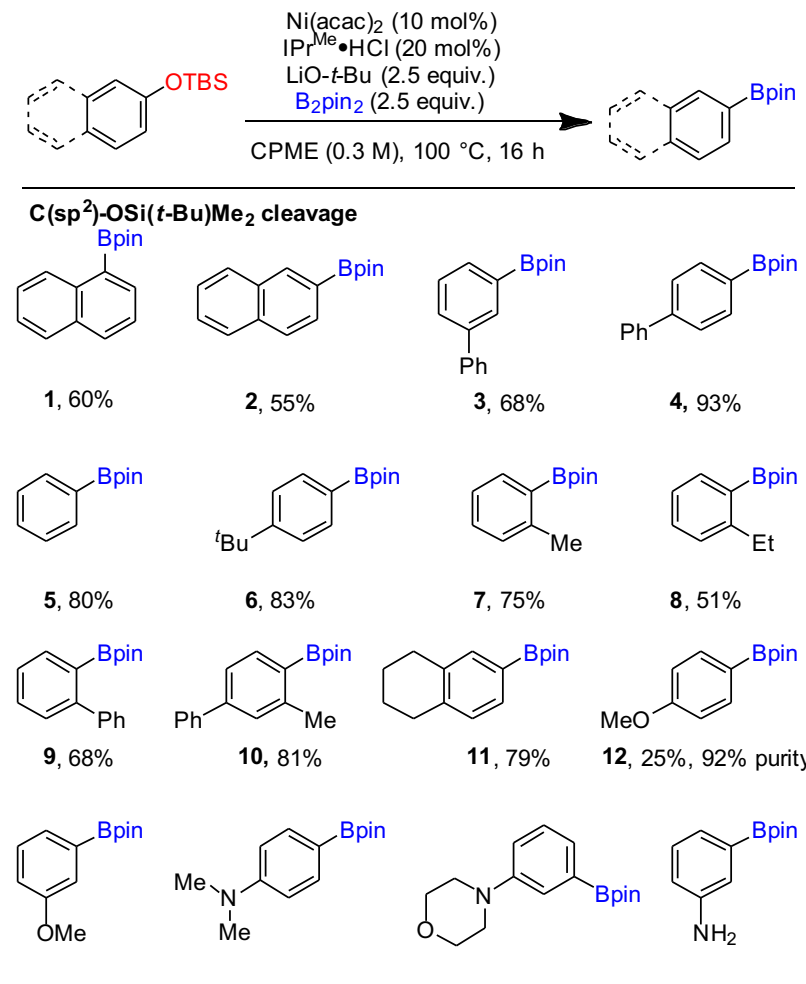

$13,65 \%$

$14,40 \%$

$15,83 \%$

$16,28 \%$

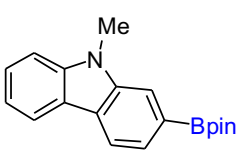

$17,76 \%$

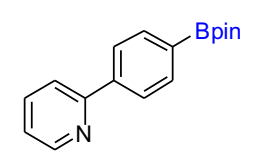

$18,49 \%$

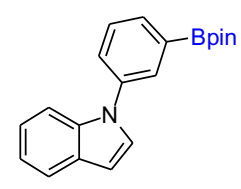

$19,57 \%$
Notably, methyl ethers, which can serve as electrophiles in subsequent coupling reactions, were tolerated. Though in modest yield, the reaction proceeded on an unprotected aniline (compound 16, Scheme 3) and a variety of heterocycles including indoles, carbazoles, and pyridines in good yields (compounds 17-19, Scheme 3).

Benzylic silyl ethers were also effective substrates in the synthesis of benzylic boranes, providing good yields of benzyl boronic pinacol esters, even in the case of non-polyaromatic substrates (compounds 21 and 22, Scheme 4). Notably, an electron-rich methoxy group was still tolerated (compound 23, Scheme 4). While yields for benzylic substrates are moderate, the borylation of methyl ethers cannot tolerate benzylic methyl ethers that contain isolated aromatic systems, representing an advancement in the area. ${ }^{15}$ Although the reaction conditions performed well on a range of substrates, the reaction did have limitations (see Table S3), especially regarding substrates with electron-withdrawing substituents.
Scheme 4. Examples of C(sp3)-O Borylation.

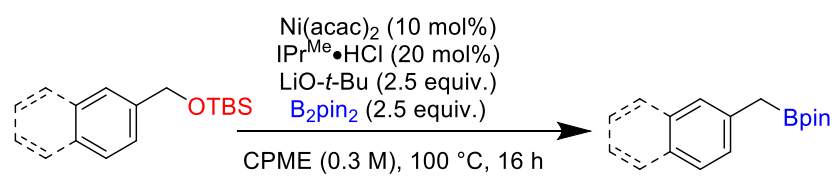

$\mathrm{C}\left(\mathrm{sp}^{3}\right)-\mathrm{OSi}(\mathrm{t}-\mathrm{Bu}) \mathrm{Me}_{2}$ cleavage

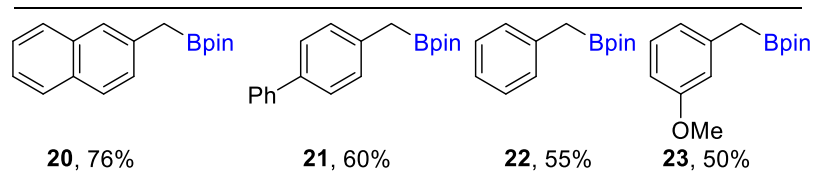

To highlight the synthetic utility of this method, we were interested in demonstrating how the orthogonal reactivity of silyloxyarenes in the presence of competing functional groups commonly used in cross couplings could be leveraged in chemoselective couplings. Achieving selectively between various $\mathrm{C}\left(\mathrm{sp}^{2}\right)-\mathrm{O}$ and $\mathrm{C}\left(\mathrm{sp}^{3}\right)-\mathrm{O}$ bonds was examined (Scheme 5). Firstly, the stability of silyloxyarenes under palladium catalysis was shown, as 24 (Scheme 5a) underwent Buchwald-Hartwig amination to afford 25 (Scheme 5a) in good yield. ${ }^{20}$ The unfunctionalized silyloxyarene participated in the borylation reaction under standard conditions to afford 19 (Scheme 5a) in moderate yield. Secondly, experiments were run to determine if the borylation of silyloxyarenes was selective for either the $\mathrm{sp}^{2}$ $\mathrm{C}-\mathrm{O}$ or the $\mathrm{sp}^{3} \mathrm{C}-\mathrm{O}$ (Scheme $5 \mathrm{~b}$ ). To probe this, 26 (Scheme $5 b)$ was subjected to the standard borylation conditions, which resulted in the formation of $\mathbf{2 9}$ (Scheme 5b) in good yield. However, borylation of the benzyl position was also observed, resulting in an inseparable mixture. To further demonstrate the advantages of this scaffold, 26 (Scheme 5b) was also subjected to amination conditions, which were previously reported, resulting in a high yield of 27 (Scheme 5b) with no evidence of overamination.

The $\mathrm{sp}^{3} \mathrm{C}-\mathrm{O}$ bond could then be subsequently functionalized to afford the borylated compound in good yield 28 (Scheme 5b). Overall, this represents a highly modular process and allow access to a generous level of diversity with regards to providing highly functionalizable biphenyl core-scaffolds, which are ubiquitous in pharmaceuticals. For example, the structure 28 represents a fragment related to the core structure of fexaramine, which is a drug currently under investigation as an agonist of the farnesoid $\mathrm{X}$ receptor. ${ }^{21}$

A plausible mechanism for this reaction involves a traditional $\mathrm{Ni}(0) / \mathrm{Ni}(\mathrm{II})$ cycle, wherein oxidative addition to the silyloxyarene would occur, followed by transmetallation of the diboron species and reductive elimination to from the borylated arene. The difficulty of engaging electron-withdrawing substrates is surprising since electron deficient electrophiles typically aid the $\mathrm{Ni}(0) / \mathrm{Ni}(\mathrm{II})$ oxidative addition step. Other mechanistic alternatives, such as a Ni(I) cycle in analogy from mechanistic proposals from Hosoya in the borylation of aryl fluorides, are potentially more consistent with the observed substrate scope and the requirement for a large excess of diboron species (see Scheme S1 for details). ${ }^{22-24}$ 
Scheme 5. Synthetic demonstrations.

5a. Orthogonal reactivity between aryl bromides and silyloxyarenes.

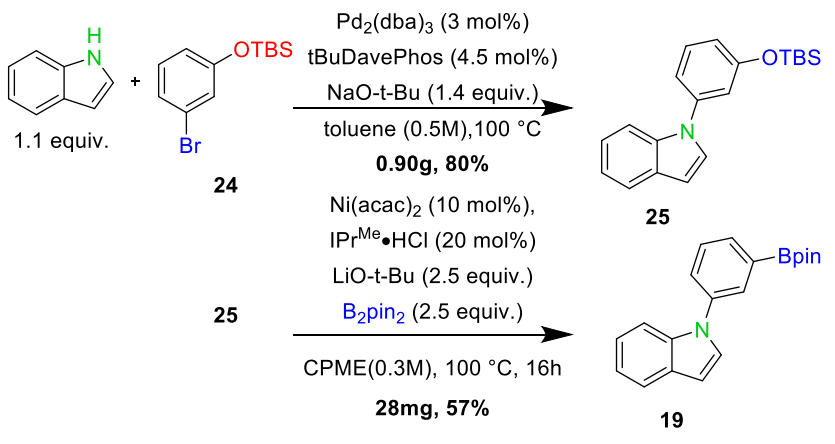

5b. Divergent functionalization of biphenyl scaffold.

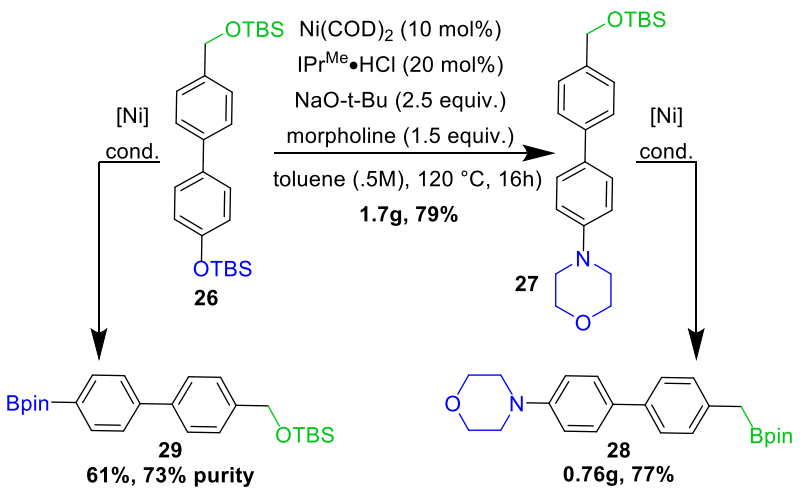

Conditions: Ni(acac)2 (10 mol\%), IPrMe.HCl (20 mol\%), LiO-t$\mathrm{Bu}$ (2.5 equiv.), $\mathrm{B}_{2} \mathrm{pin}_{2}$ (2.5 equiv.), cyclopentylmethylether (0.3M), $100{ }^{\circ} \mathrm{C}, 16 \mathrm{~h}$.

In summary, a versatile nickel-catalyzed ipso-borylation of silyloxyarenes and silyl ethers has been developed. This method is distinguished by the inclusion of several isolated aromatic substrates, heterocycles, and the activation of sp3 $\mathrm{C}-\mathrm{O}$ bonds under relatively mild reaction conditions. These features address a number of the limitations of alternative approaches for the catalytic functionalization of low-reactivity $\mathrm{C}-\mathrm{O}$ bonds in $\mathrm{C}(\mathrm{sp} 2)-\mathrm{O}$ couplings. The use of bis(pinacolato)diboron to afford the corresponding pinacol boronic ester provides a desirable balance between stability and reactivity, as boronic esters are easily isolated and stored while still being reactive enough to participate in downstream functionalization. Finally, the orthogonality of this method to other classes of arene and heteroarene cross couplings was highlighted by several examples wherein the silyl ether was found to be inert under BuchwaldHartwig aminations of aryl bromides. Additionally, excellent selectivity was seen in the case of the borylation of an $\mathrm{sp} 2 \mathrm{C}-\mathrm{O}$ over an $\mathrm{sp} 3 \mathrm{C}-\mathrm{O}$ bond. This method represents a viable strategy to functionalize a broad scope of silyloxyarenes, featuring excellent selectivity of poly-electrophilic systems, rendering it suitable for use in late-stage diversification strategies.

\section{ASSOCIATED CONTENT}

\section{Supporting Information}

Synthetic details and spectral data. This material is available free of charge via the Internet at http://pubs.acs.org.

\section{AUTHOR INFORMATION}

\section{Corresponding Author}

John Montgomery - Department of Chemistry, University of Michigan, Ann Arbor, Michigan 48109-1055, United States; orcid.org/0000-0002-2229-0585; E-mail: jmontg@umich.edu
Authors
Wesley Pein - Department of Chemistry, University of Michi- gan, Ann Arbor, Michigan 48109-1055, United States;

Eric Wiensch - Department of Chemistry, University of Michigan, Ann Arbor, Michigan 48109-1055, United States;

Complete contact information is available at:

\section{Notes}

The authors declare no competing financial interest

\section{ACKNOWLEDGMENT}

The authors thank the National Science Foundation (CHE-1954939) including an AGEP-GRS supplement (for W.L.P.) in support of this research.

\section{REFERENCES}

(1) Ludwig, J.; Schindler, C. Chem. 2017, 2, 313-316.

(2) (a) Montgomery, J. "Organonickel Chemistry" in Organometallics in Synthesis: Fourth Manual Lipshutz, B. H. (Ed.) Wiley, Hoboken, N. J. 2013, pp. 319-428. (b) Tasker, S.; Standley, E.; Jamison, T. Nature, 2014, 509, 299-309.

(3) (a) Bajo, S.; Laidlaw, G.; Kennedy, A.; Sproules, S.; Nelson, D. Organometallics, 2017, 36, 1662-1672. (b) Fricke, C. Schoenebeck, F. Acc. Chem. Res. 2020, 53, 2715-2724. (c) Entz, E. D.; Russell, J. E. A.; Hooker, L. V.; Neufeldt, S. R. J. Am. Chem. Soc. 2020, 142, 1545415463.

(4) Selected coupling methods using activated nucleophilic coupling partners with aryl ethers: a) Dankwardt, J. W. Angew. Chem. Int. Ed. 2004, 43, 2428-2432; b) Guan, B. T.; Xiang,T.Wu, S. K.; Sun, Z. P.; Wang, B. Q.; Zhao, K. Q.; Shi, Z. J.; Chem. Commun. 2008, 14371439; c) Xie, L. G.; Wang, Z. X. Chem. Eur. J. 2011, 17, 4972-4975; d) Yang, Z. K.; Wang, D. Y.; Minami, H.; Ogawa, H.; Ozaki, T.; Saito, T.; Miyamoto, K.; Wang, C.; Uchiyama, M. Chem. Eur. J. 2016, 22 , 15693-15699.

(5) Wiensch, E.; Todd, D.; Montgomery, E. ACS Catal. 2017, 7, $5568-5571$

(6) Wiensch, E.; Montgomery, J. Angew. Chem. Int. Ed. 2018, 57, 11045-11049.

(7) Selected examples of down-stream functionalizations of arylboronic acids: a) Hooshmand, S. E.; Heidari, B.; Sedghi, R.; Varma, R. S. Green Chem. 2019, 21, 381-405.; b) Wu, P.; Givskov, M.; Nielsen, T. E. Chem. Rev. 2019, 119, 11245-11290.; c) West, M.; Fyfe, J.; Vantourout, J.; Watson, A. Chem. Rev. 2019, 119, 12491-12523.

(8) Trippier, P.; McGuigan, C. Med. Chem. Commun. 2010, 1, 183198.

(9) Selected organometallic synthesis of aryl boronic acids: a) Leermann, T.; Leroux, F. R.; Colobert, F. Org. Lett. 2011, 13, 44794481.; b) Hafner, A. Meisenbach, M.; Sedelmeier, J. Org. Lett. 2016 18, 3630-3633.; c) Wan, C. W.; Burghart, A.; Chen, J.; Bergström, F.; Johansson, L. B. Å.; Wolford, M. F.; Kim, T. G.; Topp, M. R.; Hochstrasser, R. M.; Burgess, K. Chem. Eur. J. 2003, 9, 4430-4441.

(10) Selected examples regarding the borylation of aryl halides and aryl C-H bonds: a) Mfuh, A. M.; Doyle, J. D.; Chhetri, B.; Arman, H. D.; Larionov, O. V. J. Am. Chem. Soc. 2016, 138, 2985-2988.; b) Zhang, L.; Jiao, L. J. Am. Chem. Soc. 2019, 141, 9124-9128.; c) Jiang, M.; Yang, H.; Fu, H. Org. Lett. 2016, 18, 5248-5251.; d) Clary, J. W.; Rettenmaier, T. J.; Snelling, R.; Bryks, W.; Banwell, J.; Wipke, W. T.; Singaram, B. J. Org. Chem. 2011, 76, 9602-9610.; e) Zhang, L.; Jiao, L. J. Am. Chem. Soc. 2017, 139, 607-610.; f) Pinet, S.; Liautard, V.; Debiais, M.; Pucheault, M. Synthesis, 2017, 49, 4759-4768.; g) Lee, Y.; Baek, S. Y.; Park, J.; Kim, S. T.; Tussupbayev, S.; Kim, J.; Baik, M. H.; Cho, S. H. J. Am. Chem. Soc. 2017, 139, 976-984.; h) Nagashima, 
Y.; Takita, R.; Yoshida, K.; Hirano, K.; Uchiyama, M. J. Am. Chem. Soc. 2013, 135, 18730-18733.; i) Billingsley, K. L.; Buchwald, S. L. J. Org. Chem. 2008, 73, 5589-5591.; j) Murata, M.; Sambommatsu, T.; Watanabe, S.; Masuda, Y. Synlett, 2006, 1867-1870.; k) Zhu, W.; Ma, D. Org. Lett. 2006, 8, 261-263.; l) Leowanawat, P.; Resmerita, A. M.; Moldoveanu, C.; Liu, C.; Zhang, N.; Wilson, D. A.; Hoang, L. M.; Rosen, B. M.; Persec, V. J. Org. Chem. 2010, 75, 7822-7828.; m) Zhao, X.; Wu, M.; Liu, Y.; Cao, S. Org. Lett. 2018, 20, 5564-5568.; N) Wang, G.; Liu, L.; Wang, H.; Ding, Y. S.; Zhou, J.; Mao, S.; Li, P. J. Am. Chem. Soc. 2017, 139, 91-94.; o) Murphy, J. M.; Tzschucke, C. C.; Hartwig, J. F. Org. Lett. 2007, 9, 757-760.; p) Mkhalid, I. A. I.; JBarnard, J. H.; Marder, T. B.; Murphy, J. M.; Hartwig, J. F. Chem. Rev. 2010, 110, 890-931.

(11) Ji, H.; Cai, J.; Gan, N.; Wang, Z.; Wu, L.; Li, G.; Yi, T. Chem. Cen. J. 2018, $12,136$.

(12) Zhou, Q.; Srinivas, H.; Zhang, S.; Watson, M. J Am Chem Soc. 2016, 138, 11989-11995.

(13) Huang, K.; Yu, D. G.; Zheng, S. F.; Wu, Z. H.; Shi, Z. J. Chem. Eur. J. 2011, 17, 786-791.

(14) Quasdorf, K.; Antoft-Finch, A.; Liu, P.; Silberstein, A.; Komaromi, A.; Blackburn, T.; Ramgren, S.; Houk, K. N.; Snieckus, V.; Garg, N. J. Am. Chem. Soc. 2011, 133, 6352-6363.

(15) Zarate, C.; Manzano, R.; Martin, R.; J. Am. Chem. Soc. 2015 $137,21,6754-6757$.
(16) a) Lalonde, M.; Chan, H. Synthesis, 1985, 9 ,817-845;b) R. D. Crouch, Synth. Commun. 2013, 43, 2265-2279;c) Nelson, T. D.; Crouch, R. D. Synthesis, 1996, 9, 1031-1069;d) Crouch, R. D. Tetrahedron, 2004, 60, 5833-5871.

(18) Wititsuwannakul, T.; Tantirungrotechai, Y.; Surawatanawong, P. ACS Catal. 2016, 6, 1477-1486.

Furukawa, T.; Tobisu, M.; Chatani, N. Chem. Commun. 2015, 51, 6508-6511.

(19) Zhang, H.; Hagihara, S.; Itami, K. Chem. Lett. 2015, 44, 779781.

(20) Old, D.; Harris, M.; Buchwald, S. Org. Lett., 2000, 2, 14031406.

(21) Downes, M.; Verdecia, M.; Roecker, A.; Hughes, R.; Hogenesch, J.; Kast-Woelbern, H.; Bowman, M.; Ferrer, J.; Anisfeld, A.; Edwards, P.; Rosenfeld, J.; Alvarez, J.; Noel, J.; Nicolaou, K.; Evans, R. Mol. cell. 2003, 11, 1079-1092.

(22) Cornella, J.; Gomez-Bengoa, E.; Martin, R. J. Am. Chem. Soc. 2013, 135, 1997-2009.

(23) Cordova, M.; Wodrich, M.; Meyer, B.; Sawatlon, B.; Corminboeuf, C. ACS Catal. 2020, 10, 7021-7031.

(24) Niwa, T.; Ochiai, H.; Watanabe, Y.; Hosoya, T. J. Am. Chem. Soc. 2015, 137, 14313-14318. 
